\title{
Use of rotational Raman measurements in multiwavelength aerosol lidar for evaluation of particle backscattering and extinction
}

\author{
I. Veselovskii ${ }^{1}$, D. N. Whiteman ${ }^{2}$, M. Korenskiy ${ }^{1,4}$, A. Suvorina ${ }^{1}$, and D. Pérez-Ramírez ${ }^{2,3}$ \\ ${ }^{1}$ Physics Instrumentation Center of General Physics Institute, Troitsk, Moscow, Russia \\ ${ }^{2}$ NASA Goddard Space Flight Center, Greenbelt, MD, USA \\ ${ }^{3}$ Universities Space Research Association, Columbia, MD, USA \\ ${ }^{4}$ Far Eastern Federal University, Russia \\ Correspondence to: I. Veselovskii (igorv@pic.troitsk.ru)
}

Received: 7 May 2015 - Published in Atmos. Meas. Tech. Discuss.: 2 July 2015

Revised: 2 September 2015 - Accepted: 21 September 2015 - Published: 7 October 2015

\begin{abstract}
Vibrational Raman scattering from nitrogen is commonly used in aerosol lidars for evaluation of particle backscattering $(\beta)$ and extinction $(\alpha)$ coefficients. However, at mid-visible wavelengths, particularly in the daytime, previous measurements have possessed low signal-to-noise ratio. Also, vibrational scattering is characterized by a significant frequency shift of the Raman component, so for the calculation of $\alpha$ and $\beta$ information about the extinction Ångström exponent is needed. Simulation results presented in this study demonstrate that ambiguity in the choice of Ångström exponent can be the a significant source of uncertainty in the calculation of backscattering coefficients when optically thick aerosol layers are considered. Both of these issues are addressed by the use of pure-rotational Raman (RR) scattering, which is characterized by a higher cross section compared to nitrogen vibrational scattering, and by a much smaller frequency shift, which essentially removes the sensitivity to changes in the Ångström exponent. We describe a practical implementation of rotational Raman measurements in an existing Mie-Raman lidar to obtain aerosol extinction and backscattering at $532 \mathrm{~nm}$. A $2.3 \mathrm{~nm}$ width interference filter was used to select a spectral range characterized by low temperature sensitivity within the anti-Stokes branch of the RR spectrum. Simulations demonstrate that the temperature dependence of the scattering cross section does not exceed $1.5 \%$ in the $230-300 \mathrm{~K}$ range, making correction for this dependence quite easy. With this upgrade, the NASA GSFC multiwavelength Raman lidar has demonstrated useful $\alpha_{532}$ measurements and was used for regular observations. Exam-
\end{abstract}

ples of lidar measurements and inversion of optical data to the particle microphysics are given.

\section{Introduction}

Atmospheric aerosols influence the radiative budget of the earth, and the corresponding forcing depends on the vertical distribution of particle scattering properties (IPCC, 2013; Guan et al., 2010). The ability of the lidar technique to provide estimates of the vertical variability of particle parameters is therefore of current interest in understanding the radiative effects of aerosols. As a demonstration of this, numerous theoretical and experimental studies applying the multiwavelength lidar technique to the analysis of different atmospheric events - such as dust intrusion, forest fire smoke, and volcanic ashes - have been performed (e.g., Tesche et al., 2009; Rolf et al., 2012; David et al., 2013). Profiles of particle parameters can be obtained through the synergy of lidar and sun photometer measurements (Wagner et al., 2013; Lopatin et al., 2013; Granados-Muñoz et al., 2014) or from multiwavelength lidar measurements alone (Ansmann and Müller, 2005; Veselovskii et al., 2013; Müller et al., 1999, 2014). In this last case, particle backscattering $(\beta)$ and extinction $(\alpha)$ coefficients measured at multiple wavelengths with Raman or high-spectral-resolution lidars (HSRLs) are inverted to particle microphysics (Ansmann and Müller, 2005). The system most often used for such measurements, due to its relative simplicity, is a Raman lidar based on a tripled Nd:YAG laser, which provides three backscattering 
$(355,532,1064 \mathrm{~nm})$ and two extinction $(355,532 \mathrm{~nm})$ coefficients. To get this so-called $3 \beta+2 \alpha$ data set, the backscatter signals are measured simultaneously with nitrogen vibrational Raman ones at 387 and $608 \mathrm{~nm}$. While high-signalto-noise measurements of nitrogen vibrational scattering at $387 \mathrm{~nm}$ during both daytime and nighttime have been possible using the narrowband, narrow-field-of-view approach (Whiteman et al, 2007), the use of vibrational Raman scattering at $608 \mathrm{~nm}$ has posed certain problems. First of all, the cross section of vibrational Raman scattering is approximately a factor of 1700 lower (considering a stimulating wavelength of $532 \mathrm{~nm}$ ) compared to the Rayleigh one (Inaba, 1976), which limits the range and temporal resolution of the measurements. Daytime skylight values are also typically higher at 608 than at $387 \mathrm{~nm}$. Another issue related to Raman nitrogen measurements at both 387 and $608 \mathrm{~nm}$ is the significant wavelength shift of the nitrogen Raman component with respect to the laser line. As a result, information about the spectral dependence of aerosol extinction is needed when $\alpha$ and $\beta$ are computed (Ansmann et al., 1992), which can be an additional source of uncertainty. A well-known solution for both of these issues is the use of HSRL (Eloranta, 2005). The recent results provided by the NASA LaRC airborne lidar demonstrate the possibility of reliable HSRL operation at both 355 and $532 \mathrm{~nm}$ (Müller et al., 2014). However such lidars, due to their complexity and cost, are still rare instruments. At the same time, there are numerous existing Raman lidars which can potentially be upgraded to improve on the weak vibrational Raman scattering measurements at $608 \mathrm{~nm}$. One of the ways this can be accomplished is to use pure-rotational Raman (RR) scattering instead of vibrational scattering. The small spectral separation of the elastic and RR components of the signal implies that aerosol backscatter and extinction can be obtained without information about the Ångström exponent. Furthermore, the total cross section of nitrogen pure RR scattering exceeds that of vibrational scattering by approximately a factor 32 for the $337.1 \mathrm{~nm}$ laser wavelength, if all rotational lines are integrated (Inaba, 1976).

Pure rotational Raman scattering is widely used in laser remote sensing for the measurement of atmospheric temperature (e.g., Behrendt and Reichardt, 2000; Balin et al., 2004; Di Girolamo et al., 2004; Arshinov et al., 2005; Radlach et al., 2008), where the pure RR and elastic signals are generally separated by the use of narrowband interference filters or diffraction-grating spectrometers. Rotational Raman scattering can also be used for the particle extinction and backscattering calculation (e.g., Kim and Cha, 2007; Achtert et al., 2013). However, an important consideration in the use of RR measurements for calculating extinction and backscattering is the temperature dependence of the RR spectra of $\mathrm{N}_{2}$ and $\mathrm{O}_{2}$ molecules. This issue in principle can be resolved by using the sum of lidar returns from the Stokes and anti-Stokes branches, which is essentially temperature independent (Penny et al., 1974). The total RR return can be collected by using, for example, double diffraction grating polychromators (e.g., Arshinov et al., 2005; Kim and Cha, 2007), though measuring all Stokes and anti-Stokes lines with equal efficiency is technologically difficult and the spectral bandwidth of such a RR channel would be quite large. Temperature-independent RR signals can be also obtained by isolating in separate channels the lines which possess opposite temperature sensitivity for atmospheric temperature profiling and combining those separate signals into a balanced sum (Behrendt et al., 2002; Di Giloramo et al., 2006). Still both of these approaches are quite complicated to be used for upgrading existing multiwavelength systems.

The alternate approach considered in this paper is to select a portion of the RR spectrum characterized by low temperature sensitivity inside one of the spectral branches. Such an approach simplifies the implementation of a RR channel in conventional multiwavelength Raman lidar systems without significant modification of the receiver design. Selection of the RR lines is done by use of a wide-band interference filter which transmits the desired portion of the RR spectrum. Centering the filter transmission band near the temperatureinsensitive RR lines decreases the temperature sensitivity of the RR scattering cross section to a level appropriate for tropospheric measurements. We should mention that with such an approach the edge of the interference filter transmission band is located close to the laser line, so blocking the elastic scattering component from penetrating into the RR channel is technologically more demanding compared to the measurements of vibrational scattering. However, the present state of optical coatings technology allows for the manufacturing of interference filters with high transmission and blocking characteristics adequate for this task.

This paper is structured as follows: in Sect. 2 we consider the general expressions for the computation of $\alpha$ and $\beta$. Sect. 3 presents an analysis of uncertainties related to the choice of the Ångström exponent when nitrogen vibrational Raman measurements are used. Our approach to implementing RR observations and first measurement results are given in Sect. 4.

\section{Calculation of particle extinction and backscattering from Mie-Raman lidar measurements}

The possibility of independent calculation of aerosol backscattering and extinction coefficients from simultaneously measured elastic and vibrational Raman backscatters was first demonstrated by Ansmann et al. (1992). Later it was shown (Whiteman, 2003a, b) that the effects related to the temperature dependence of pure-rotational and vibrationalrotational Raman scattering should be taken into account when considering measurements of Rayleigh-Mie and Raman lidar. That temperature dependence will be considered later in this paper, and a correction for the effects of temperature dependence of rotational Raman scattering will be 
developed. For this reason, we introduce the temperaturedependent lidar equation for Raman scattering here. For the heights corresponding to full geometrical overlap the power of elastic $\left(P_{L}\right)$ and Raman $\left(P_{\mathrm{R}}\right)$ backscatter signals received from distance $z$ can be calculated as

$$
\begin{aligned}
& P_{L}(z)=\frac{1}{z^{2}} K_{\mathrm{L}}\left(\beta_{\mathrm{L}}^{\mathrm{aer}}(z)+\beta_{\mathrm{L}}^{\mathrm{mol}}(z)\right) \\
& \cdot \exp \left\{-2 \int_{0}^{z}\left(\alpha_{\mathrm{L}}^{\mathrm{aer}}\left(z^{\prime}\right)+\alpha_{\mathrm{L}}^{\mathrm{mol}}\left(z^{\prime}\right)\right) \mathrm{d} z^{\prime}\right\}, \\
& P_{\mathrm{R}}(z)=\frac{1}{z^{2}} K_{\mathrm{R}} F_{\mathrm{R}}(T(z)) \sigma_{\mathrm{L}}^{\mathrm{mol}} N(z) \\
& \cdot \exp \left\{-\int_{0}^{z}\left[\left(\alpha_{\mathrm{L}}^{\mathrm{aer}}\left(z^{\prime}\right)+\alpha_{\mathrm{R}}^{\mathrm{aer}}\left(z^{\prime}\right)\right)+\left(\alpha_{\mathrm{L}}^{\mathrm{mol}}\left(z^{\prime}\right)+\alpha_{\mathrm{R}}^{\mathrm{mol}}\left(z^{\prime}\right)\right)\right] \mathrm{d} z^{\prime}\right\} .
\end{aligned}
$$

$K_{\mathrm{L}, \mathrm{R}}$ are range-independent system parameters, indices "aer" and "mol" here correspond to the aerosol and molecular components of backscattering and extinction coefficients, and indices " $L$ " and "R" correspond to the laser and Raman component wavelengths $\lambda_{L}, \lambda_{R}$. Here, in order to generalize the notation, we use $\sigma_{\mathrm{L}}^{\mathrm{mol}}$ to refer to the sum of Cabannes, rotational and vibrational Raman contributions to the molecular differential cross section. The specific measurement (e.g., Rayleigh, rotational or vibrational Raman) is then determined by the channel bandpass characteristics as given in $F_{\mathrm{R}}(T)$ below. $N(z)$ is the molecular number density. The temperature-dependent factor $F_{\mathrm{R}}(T(z))$ is introduced in the same way as was done in Whiteman (2003a):

$F_{\mathrm{R}}(T)=\frac{\int_{\Delta \lambda} \frac{d \sigma_{\mathrm{L}}^{\mathrm{mol}}(\lambda, T)}{d \lambda} \xi_{\mathrm{R}}(\lambda) \mathrm{d} \lambda}{\sigma_{\mathrm{L}}^{\mathrm{mol}}}$

Here $\xi_{R}(\lambda)$ is the spectral transmission of the Raman channel, selecting the vibrational-rotational or pure-rotational part of the spectrum. The temperature-dependent factor can in principle be introduced also for the molecular backscattering in the equation for $\mathrm{P}_{L}(\mathrm{z})$ shown in Eq. (1). However for the receivers with narrowband interference filters centered at the laser wavelength, this effect can generally be neglected except for the case of very light aerosol loading (Whiteman, 2003a). Here we consider cases with higher loadings that are suitable for microphysical inversions and neglect this effect.
The particle backscattering and extinction coefficients can be calculated from Eqs. (1) and (2) as

$$
\begin{aligned}
& \beta_{\mathrm{L}}^{\mathrm{aer}}(z)=-\beta_{\mathrm{L}}^{\mathrm{mol}}(z)+\beta_{\mathrm{L}}^{\mathrm{mol}}\left(z_{0}\right) \cdot \frac{P_{\mathrm{R}}\left(z_{0}\right) P_{L}(z) N(z) F_{\mathrm{R}}(z)}{P_{L}\left(z_{0}\right) P_{\mathrm{R}}(z) N\left(z_{0}\right) F_{\mathrm{R}}\left(z_{0}\right)} \\
& \cdot \exp \left\{\int_{z_{0}}^{z}\left[\alpha_{\mathrm{L}}^{\mathrm{aer}}\left(1-\left(\frac{\lambda_{\mathrm{L}}}{\lambda_{\mathrm{R}}}\right)^{A}\right)+\left(\alpha_{\mathrm{L}}^{\mathrm{mol}}-\alpha_{\mathrm{R}}^{\mathrm{mol}}\right)\right] \mathrm{d} z^{\prime}\right\},
\end{aligned}
$$

$\alpha_{\mathrm{L}}^{\mathrm{aer}}(z)=\frac{\frac{\mathrm{d}}{\mathrm{d} z} \ln \left(\frac{N(z)}{P_{\mathrm{R}}(z) \cdot z^{2}}\right)+\frac{\mathrm{d}}{\mathrm{d} z} \ln F_{\mathrm{R}}(z)-\alpha_{\mathrm{L}}^{\mathrm{mol}}(z)-\alpha_{\mathrm{R}}^{\mathrm{mol}}(z)}{1+\left(\frac{\lambda_{\mathrm{R}}}{\lambda_{\mathrm{L}}}\right)^{A}}$.

The reference height $z_{0}$ is usually chosen in the free troposphere where $\beta_{\mathrm{L}}^{\text {aer }}\left(z_{0}\right) \ll \beta_{\mathrm{L}}^{\text {mol }}\left(z_{0}\right)$. To account for the spectral dependence of extinction coefficient the Ångström exponent $A$ is used:

$\frac{\alpha^{\mathrm{aer}}\left(\lambda_{\mathrm{L}}\right)}{\alpha^{\mathrm{aer}}\left(\lambda_{\mathrm{R}}\right)}=\left(\frac{\lambda_{\mathrm{R}}}{\lambda_{\mathrm{L}}}\right)^{A}$.

For further consideration it is convenient to introduce the effective Raman backscattering cross section:

$\sigma_{\mathrm{R}}^{\mathrm{eff}}=\int_{\Delta \lambda} \frac{\mathrm{d} \sigma_{\mathrm{L}}^{\mathrm{mol}}(\lambda, T)}{\mathrm{d} \lambda} \xi_{\mathrm{R}}(\lambda) \mathrm{d} \lambda$

Then the ratio $\frac{F_{\mathrm{R}}(z)}{F_{\mathrm{R}}\left(z_{0}\right)}=\frac{\sigma_{\mathrm{R}}^{\text {eff }}(z)}{\sigma_{\mathrm{R}}^{\text {eff }}\left(z_{0}\right)}$ is the ratio of effective cross sections at height $z$ and $z_{0}$, characterized by temperatures $T$ and $T_{0}$, respectively. For vibrational Raman scattering the deviation of the ratio $\frac{F_{\mathrm{R}}(z)}{F_{\mathrm{R}}\left(z_{0}\right)}$ from 1 can be neglected, as can the contribution provided by the term $\frac{\mathrm{d}}{\mathrm{d} z} \ln F_{\mathrm{R}}(z)$ in Eq. (5; Whiteman, 2003a). However for pure-rotational scattering, when only a part of the RR spectra is selected, the temperature (and hence height) dependence of $\frac{F_{\mathrm{R}}(z)}{F_{\mathrm{R}}\left(z_{0}\right)}$ and $\frac{\mathrm{d}}{\mathrm{d} z} \ln F_{\mathrm{R}}(z)$ can be important. The corresponding effects of these temperature dependencies will be considered in the Sect. 4 .

\section{Sensitivity of extinction and backscattering calculation to the choice of Ångström exponent}

The spectral dependence of particle extinction can be neglected when pure-rotational Raman scattering is used; however for vibrational scattering, which is characterized by a significant wavelength shift of the Raman component, the ambiguity in the choice of the Ångström exponent is an additional source of uncertainty in the $\beta^{a}$ and $\alpha^{a}$ calculations. This uncertainty was considered before for measurements acquired at $351 \mathrm{~nm}$ (Whiteman, 2003a, b). Here we consider the case for the 355 and $532 \mathrm{~nm}$ wavelengths of the $3 \beta+2 \alpha$ lidar system.

As follows from Eq. (5), the uncertainty in the computation of aerosol extinction $\varepsilon_{\alpha}$ due to the choice of Ångström 
Table 1. Extinction Ångström exponents at 355-532, 355-387, and 532-608 nm wavelengths for distributions with different ratios $\frac{N_{\mathrm{f}}}{N_{\mathrm{c}}}$ and different values of refractive index.

\begin{tabular}{lrrrr}
\hline & & \multicolumn{3}{c}{ Angström exponent } \\
\cline { 3 - 5 } Aerosol type & Refractive index & $A_{355-532}$ & $A_{355-387}$ & $A_{532-608}$ \\
\hline \multirow{3}{*}{$N_{\mathrm{f}}=10^{4}$} & $1.35-i 0.005$ & 1.62 & 1.39 & 1.98 \\
& $1.45-i 0.005$ & 1.32 & 1.03 & 1.79 \\
& $1.6-i 0.005$ & 0.87 & 0.52 & 1.47 \\
& $1.6-i 0.05$ & 0.78 & 0.46 & 1.30 \\
\hline \multirow{3}{*}{$N_{\mathrm{f}}$} & $1.35-i 0.005$ & 1.40 & 1.24 & 1.58 \\
$N_{\mathrm{c}}=10^{3}$ & $1.45-i 0.005$ & 1.15 & 0.92 & 1.46 \\
& $1.6-i 0.005$ & 0.81 & 0.48 & 1.33 \\
& $1.6-i 0.05$ & 0.72 & 0.43 & 1.18 \\
\hline \multirow{3}{*}{$N_{\mathrm{f}}$} & $1.35-i 0.005$ & 0.58 & 0.59 & 0.48 \\
\hline$N_{\mathrm{c}}$ & $1.45-i 0.005$ & 0.426 & 0.41 & 0.59 \\
& $1.6-i 0.005$ & 0.44 & 0.28 & 0.64 \\
& $1.6-i 0.05$ & 0.39 & 0.24 & 0.57 \\
\hline
\end{tabular}

exponent depends on the ratio $\left(\frac{\lambda_{R}}{\lambda_{L}}\right)^{A}$, and for a constant $A$ this uncertainty is range independent. The effect of the Ångström exponent on the calculation of backscattering coefficient is described by the exponent term in Eq. (4), which for height-independent $A$ can be written as

$\exp \left\{\int_{z_{0}}^{z} \alpha_{\mathrm{L}}\left(z^{\prime}\right)\left[1-\left(\frac{\lambda_{\mathrm{L}}}{\lambda_{\mathrm{R}}}\right)^{A}\right] \mathrm{d} z^{\prime}\right\}=\exp \left\{D(z)\left[1-\left(\frac{\lambda_{\mathrm{L}}}{\lambda_{\mathrm{R}}}\right)^{A}\right]\right\}$,

where $D(z)=\int_{z_{0}}^{z} \alpha_{\mathrm{L}}\left(z^{\prime}\right) \mathrm{d} z^{\prime}$ is the aerosol optical depth for height interval $\left[\mathrm{z}_{0}, \mathrm{z}\right]$. Thus the uncertainty $\varepsilon_{\beta}$ of the backscattering coefficient calculation is integrated over distance $z_{0}-z$. Taking $\Delta A$ as the deviation of the Ångström exponent from the "true" value, $\varepsilon_{\beta}$ can be calculated from Eqs. (4) and (6) as

$$
\begin{aligned}
& \varepsilon_{\beta}=\frac{\beta^{\text {aer }}(A+\Delta A)-\beta^{\text {aer }}(A)}{\beta^{\text {aer }}(A)}=\frac{\beta^{\text {tot }}(A+\Delta A)-\beta^{\text {tot }}(A)}{\beta^{\text {tot }}(A)-\beta^{\mathrm{mol}}} \\
& =\beta^{\text {tot }}(A) \frac{\exp \left\{D\left(\frac{\lambda_{\mathrm{L}}}{\lambda_{\mathrm{R}}}\right)^{A}\left(1-\left(\frac{\lambda_{\mathrm{L}}}{\lambda_{\mathrm{R}}}\right)^{\Delta A}\right)\right\}-1}{\beta^{\mathrm{tot}}(A)-\beta^{\mathrm{mol}}} \\
& =\frac{R}{R-1}\left(\exp \left\{D\left(\frac{\lambda_{\mathrm{L}}}{\lambda_{\mathrm{R}}}\right)^{A}\left(1-\left(\frac{\lambda_{\mathrm{L}}}{\lambda_{\mathrm{R}}}\right)^{\Delta A}\right)\right\}-1\right)
\end{aligned}
$$

Here $\beta^{\text {tot }}=\beta^{\text {aer }}+\beta^{\text {mol }}$ and $R$ is the scattering ratio $\frac{\beta^{\text {tot }}}{\beta^{\text {mol }}}$. For high aerosol loading, when $\beta_{\mathrm{L}}^{\text {aer }}>>\beta_{\mathrm{L}}^{\text {mol }}$, the ratio $\frac{R}{R-1} \approx 1$ and $\varepsilon_{\beta}$ rises quickly with increasing optical depth $D$ and $\Delta A$. However in the UV and visible spectral ranges the magnitude of molecular and aerosol backscattering outside of clouds can be comparable, so the influence of molecular scattering on $\varepsilon_{\beta}$ must be considered. For estimating the uncertainty $\varepsilon_{\beta}$ for
Table 2. Uncertainties of extinction $\varepsilon_{\alpha}$ at 355 and $532 \mathrm{~nm}$ for different values of Ångström exponent $A$ chosen in computations. Results are shown for $m=1.45-i 0.005$.

\begin{tabular}{lrrrr}
\hline & \multicolumn{2}{c}{$355 \mathrm{~nm}$} & \multicolumn{2}{c}{$532 \mathrm{~nm}$} \\
\cline { 2 - 5 }$A$ & $A-A^{\text {mod }}$ & $\varepsilon_{\alpha}$ & $A-A^{\text {mod }}$ & $\varepsilon_{\alpha}$ \\
\hline 0 & -1.03 & $4.5 \%$ & -1.79 & $10.5 \%$ \\
0.5 & -0.53 & $2 \%$ & -1.29 & $7.5 \%$ \\
1 & -0.03 & $0.15 \%$ & -0.79 & $4.5 \%$ \\
1.5 & 0.47 & $2 \%$ & -0.29 & $1.5 \%$ \\
2 & 0.97 & $4 \%$ & 0.21 & $1.2 \%$ \\
\hline
\end{tabular}

different laser wavelengths and aerosol loadings, numerical simulation was performed.

For simulating retrieval of particle backscattering and extinction coefficients from Mie-Raman lidar measurements a particle bimodal size distribution was represented as

$$
\frac{\mathrm{d} n(r)}{\mathrm{d} \ln (r)}=\sum_{i=\mathrm{f}, \mathrm{c}} \frac{N_{i}}{(2 \pi)^{1 / 2} \cdot \ln \sigma_{i}} \cdot \exp \left[\frac{\left(\ln r-\ln r_{0 i}\right)^{2}}{2\left(\ln \sigma_{i}\right)^{2}}\right] .
$$

Here $N_{i}$ is the total particle number of the $i$ th mode, $r_{i}$ describes the mode radius and $\ln \sigma_{i}$ is the dispersion. The index $i=\mathrm{f}$ and c corresponds to the fine and coarse mode, respectively. For all computations the values $r_{0 \mathrm{f}}=0.1 \mu \mathrm{m}$, $r_{0 \mathrm{c}}=1.2 \mu \mathrm{m}$ and $\ln \sigma_{\mathrm{f}, \mathrm{c}}=0.4$ were used and the complex refractive index (CRI) was assumed to be the same for both modes. The concentration of particles in the fine mode $N_{\mathrm{f}}$ was kept constant through all simulations, while the concentration in the coarse mode varied. The spectral dependence of the Angström exponent is influenced by the relative contributions of the fine and the coarse modes (O'Neil et al., 2001), so to evaluate this effect three types of particle size 


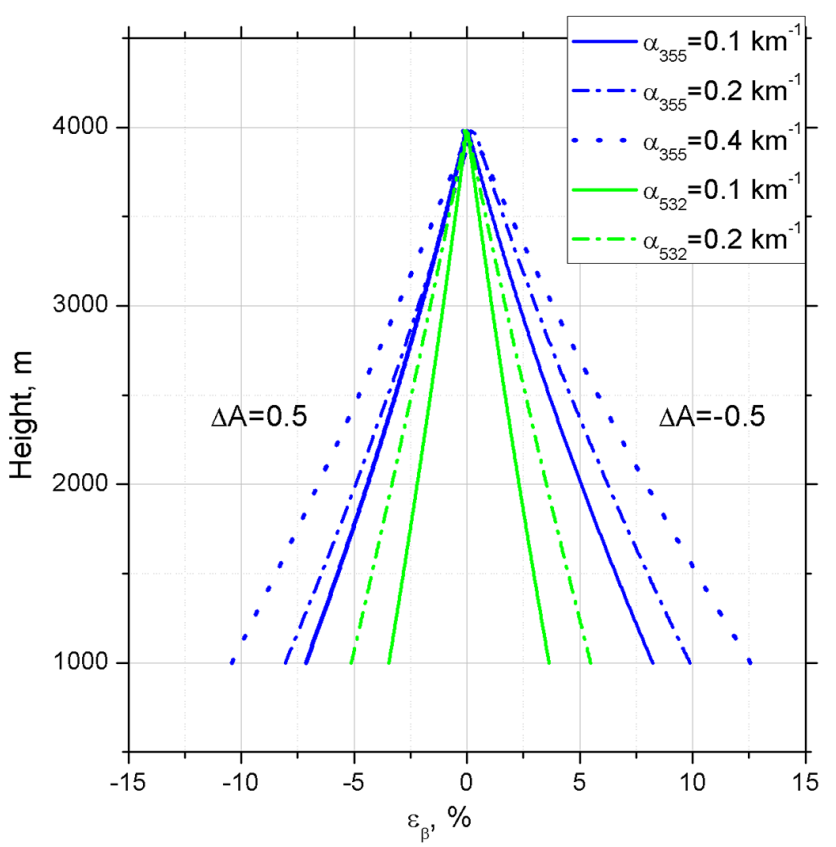

Figure 1. Profiles of backscattering coefficient uncertainties at 355 (blue) and $532 \mathrm{~nm}$ (green) for extinction coefficient $0.1 \mathrm{~km}^{-1}$ (solid), $0.2 \mathrm{~km}^{-1}$ (dash-dot), $0.4 \mathrm{~km}^{-1}$ (dot) and $\Delta A= \pm 0.5$.

distribution (PSD) were considered. For the first type (T1) with $\frac{N_{\mathrm{f}}}{N_{\mathrm{c}}}=10^{4}$ the main particle volume is attributed to the fine mode. For the second type (T2) $\frac{N_{\mathrm{f}}}{N_{\mathrm{c}}}=10^{3}$ the total volume of particles in each mode is comparable. And finally, in the distribution T3 with $\frac{N_{\mathrm{f}}}{N_{\mathrm{c}}}=10^{2}$ the coarse mode is predominant. The particle backscattering and extinction coefficients were calculated from the model size distribution using Mie theory (Bohren and Huffmann, 1983). The parameters of the fine and the coarse mode of real aerosols may exhibit strong variability (Dubovik et al., 2002); still the choice of typical values for this simulation permits us to estimate the effect of the spectral dependence of the Ångström exponent on backscattering and extinction calculation.

A Raman lidar based on a tripled Nd:YAG laser can measure the extinction Ångström exponent at 355-532 nm wavelengths $\left(A_{355}-532\right)$. However, when nitrogen vibrational Raman backscatters at 387 and $608 \mathrm{~nm}$ are used to determine backscattering coefficients at 355 and $532 \mathrm{~nm}$, the Ångström exponents $A_{355-387}$ and $A_{532-608}$ are needed, and these may differ from $A_{355-532}$. Table 1 shows the Angström exponents $A_{355-532}, A_{355-387}$, and $A_{532-608}$ for the size distributions T1-T3 and refractive indices $m=1.35-i 0.005$, $1.45-i 0.005,1.6-i 0.005$, and $1.6-i 0.05$. These values of CRI correspond to a variety of particles, such as water aerosol, biomass burning products and desert dust (Dubovik et al., 2002). The spectral dependence of the Ångström exponent is the most significant for particles with a fine-mode predominance. For the T1 distribution, the uncertainty in the choice of the Ångström exponent $\Delta A$ may exceed 0.5 when

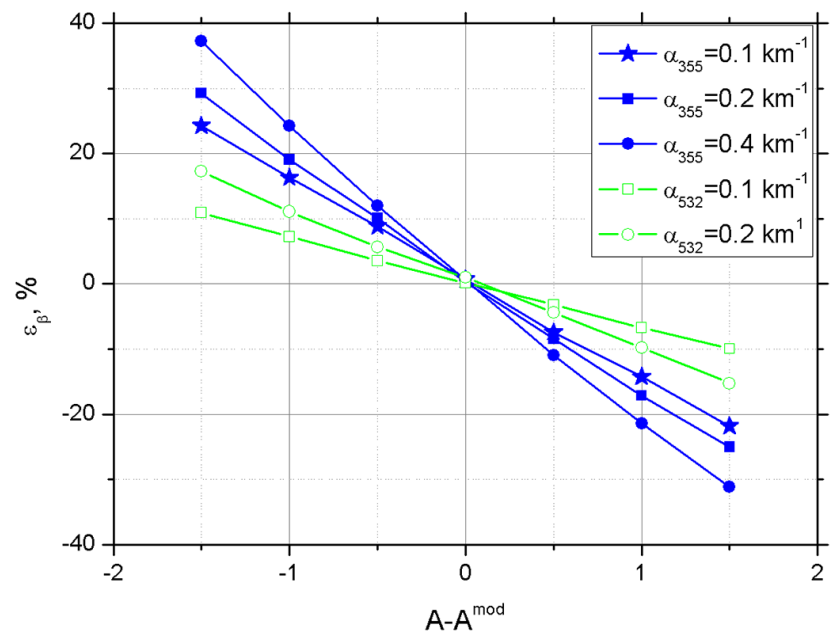

Figure 2. The uncertainty of backscattering coefficient calculation $\varepsilon_{\beta}$ at $355 \mathrm{~nm}$ (blue) and $532 \mathrm{~nm}$ (green) as a function of deviation from model value of Angstrom exponent $A-A^{\text {mod }}$. Results are given for height $z=1000 \mathrm{~m}$ and particle extinction coefficients $0.1,0.2$, and $0.4 \mathrm{~km}^{-1}$; model values are $A_{355-387}^{\bmod }=1.03$ and $A_{532-608}^{\bmod }=1.79$.

$A_{355-532}$ is used for the computation of both $\beta_{355}$ and $\beta_{532}$. For particles with a coarse-mode predominance (T3), the spectral dependence of the Ångström exponent is weaker and $\triangle A<0.2$ when $A_{355-532}$ is used.

To estimate how sensitive the backscattering coefficient is to the choice of the Ångström exponent, we considered an aerosol layer extending from the ground up to $4000 \mathrm{~m}$ with a height-independent particle concentration. As mentioned, the spectral dependence of $A$ is strongest for a PSD with a predominance of the fine mode, so the simulation results are presented for the $\mathrm{T} 1$ distribution $\left(\frac{N_{\mathrm{f}}}{N_{\mathrm{c}}}=10^{4}\right)$. The uncertainty of the backscattering calculation depends on aerosol loading; thus in the simulations different particle concentrations were considered in order to obtain extinction coefficients of $\alpha^{a}=0.1,0.2$, and $0.4 \mathrm{~km}^{-1}$ at 355 and $532 \mathrm{~nm}$. The refractive index used was $m=1.45-i .005$, and corresponding model values of $A_{355-387}, A_{532-608}$ and $A_{355-532}$ were taken from Table 1 . The backscattering and extinction coefficients for the chosen size distribution together with model molecular scattering were used to generate noise-free synthetic backscatter and nitrogen Raman lidar signals using Eqs. (1) and (2), but neglecting the temperature dependence of backscattering cross section. Then, the values of $\alpha$ and $\beta$ were back-calculated with Eqs. $(4,5)$ using Ångström exponents $A$, which differed from the model values $A^{\text {mod }}$. The systematic uncertainty for backscattering was determined as

$\varepsilon_{\beta}=\frac{\beta^{\mathrm{aer}}(A)-\beta^{\mathrm{aer}}\left(A^{\mathrm{mod}}\right)}{\beta^{\mathrm{aer}}\left(A^{\mathrm{mod}}\right)}$.

The systematic uncertainty in extinction was defined similarly. 


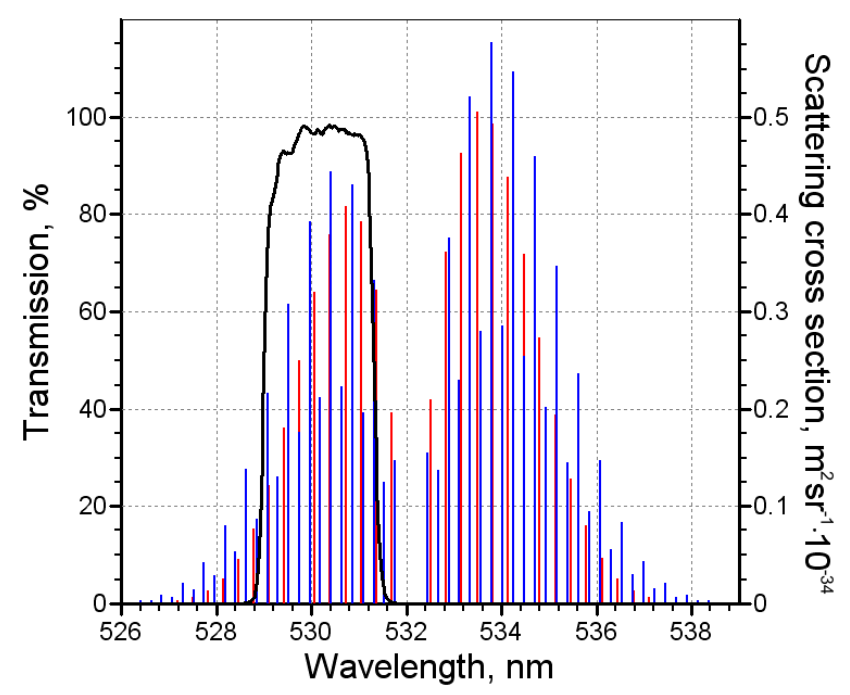

Figure 3. Spectrum of RR scattering by nitrogen (blue) and oxygen (red) for $T=300 \mathrm{~K}$ together with transmission of the interference filter used in the experiment. Backscatter cross sections of $\mathrm{N}_{2}$ and $\mathrm{O}_{2}$ lines are multiplied by 0.79 and 0.21 , respectively; laser line is at $532.12 \mathrm{~nm}$.

The results of the simulations for particle extinction are summarized in Table 2, showing $\varepsilon_{\alpha}$ at 355 and $532 \mathrm{~nm}$ for different assumed values of $A$ in range $[0,2.0]$. As mentioned, the uncertainty of extinction $\varepsilon_{\alpha}$ is independent of range or aerosol loading. Interpolating the results in Table 2, we can conclude that it is below $2 \%$ for $355 \mathrm{~nm}$ and below $3 \%$ for $532 \mathrm{~nm}$ wavelength when $A_{355-532}=1.32$ is used in the computations.

In contrast to extinction, the uncertainties $\varepsilon_{\beta}$ depend on range since the differential transmission between Raman and laser wavelengths is involved and errors in this calculation accumulate with range. The height profiles of $\varepsilon_{\beta}$ at $355 \mathrm{~nm}$ for the particle extinction coefficients $0.1,0.2$ and $0.4 \mathrm{~km}^{-1}$ are given in Fig. 1 for $\Delta A=A-A^{\text {mod }}= \pm 0.5$. For comparison, the same figure also shows results at $532 \mathrm{~nm}$ for $\alpha=0.1$ and $0.2 \mathrm{~km}^{-1}$. The uncertainty is negligible near the reference height $\left(z_{0}=4000 \mathrm{~m}\right)$, and it rises with increasing $\left|z-z_{0}\right|$. At $z=1000 \mathrm{~m}$ the uncertainties can be as high as 8 and $10 \%$ at $355 \mathrm{~nm}$ for $\alpha=0.1$ and $0.2 \mathrm{~km}^{-1}$, respectively, when $\Delta A=-0.5$. For $532 \mathrm{~nm}$ these uncertainties are 4 and $6 \%$, which is approximately a factor of 2 lower than at $355 \mathrm{~nm}$. An increase of extinction up to $\alpha=0.4 \mathrm{~km}^{-1}$ leads to a rapid increase in $\varepsilon_{\beta}$, and the correct choice of the Ångström exponent becomes more important. Figure 2 illustrates the dependence of $\varepsilon_{\beta}(\Delta A)$ at $z=1000 \mathrm{~m}$ on different values of extinction coefficient. This dependence is close to linear, so an increase of $\Delta A$ from 0.5 to $\Delta A=1$ doubles the uncertainty when compared with Fig. 1.

The simulations performed here demonstrate that the uncertainty in the choice of the Ångström exponent can be a source of significant bias in the calculation of backscatter-

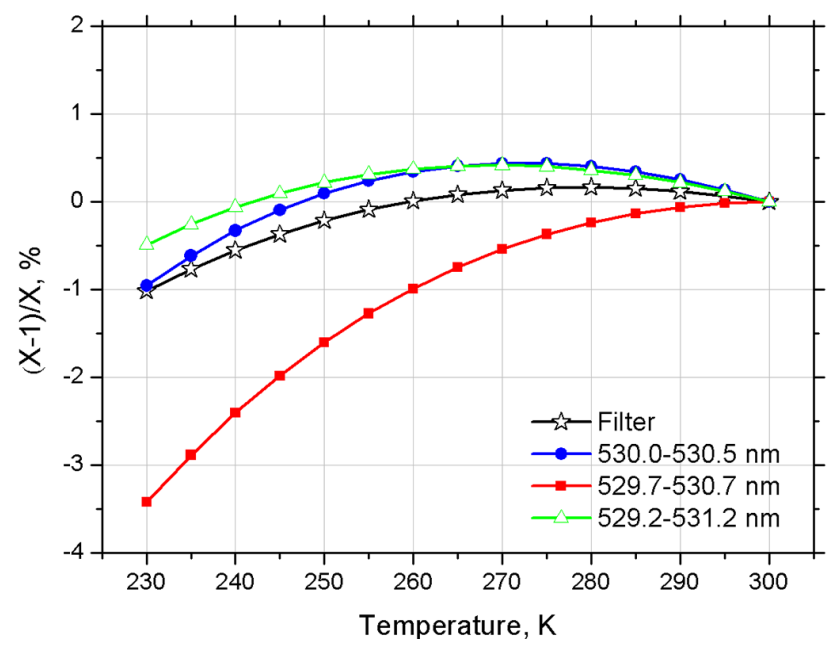

Figure 4. The relative change of RR scattering cross section $(X-$ $1) / X$ as a function of temperature for spectral range 530.0-530.5, 529.7-530.7, and 529.2-531.2 nm. Open stars show results for the interference filter used in the experiment. The reference temperature used in computations is $T_{0}=300 \mathrm{~K}$.

ing calculation when aerosol layers with high optical depth are profiled and that this effect is especially pronounced at $355 \mathrm{~nm}$. In real measurements, the situation can be even more complicated because of the vertical variability of the Ångström exponent. So it is desirable to eliminate the uncertainties related to the assumption of the $A$ value through the use of rotational Raman scattering instead of vibrational scattering, thus decreasing the frequency shift of the inelastically scattered component.

\section{Implementation of rotational Raman channel}

In this section we describe a rather simple approach for implementing a rotational Raman channel in a conventional multiwavelength lidar. The approach is tested at $532 \mathrm{~nm}$ laser wavelength.

\subsection{Temperature sensitivity of rotational Raman measurements}

In our implementation a part of the RR spectrum is selected by a steep-edge interference filter. For calculation of the effective RR backscattering cross section $\left(\sigma_{\mathrm{RR}}^{\text {eff }}\right)$ the integral in Eq. (7) can be replaced by the sum of contributions from individual rotational lines of nitrogen and oxygen. Detailed descriptions of the calculation of the RR spectrum have been presented in numerous publications (e.g., Herzberg, 1950; Long, 2002; Inaba, 1976; Penney et al., 1974; Behrendt and Nakamura, 2002; Adam, 2009). For every Stokes $(s)$ and anti-Stokes (as) line in the RR spectrum, resulting from a molecule in state $J$, the differential backscattering cross section for the sum of components with polarization parallel and 


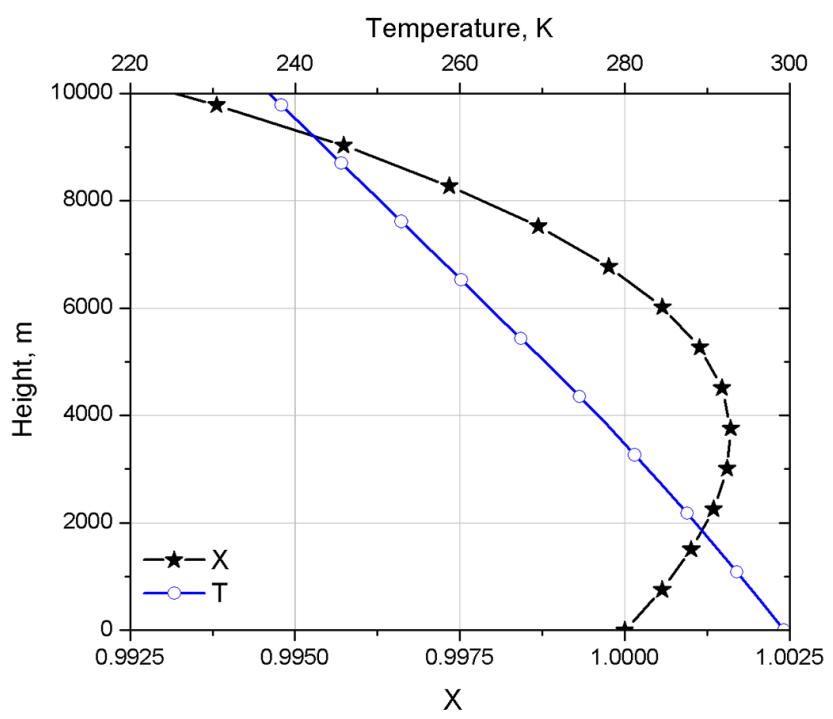

Figure 5. Vertical profile of $X$ computed on the basis of the US Standard Atmosphere model for the interference filter used. The reference height is taken at $z_{0}=0$; the open symbols mark the model temperature profile.

perpendicular to the polarization of laser beam can be expressed as

$\sigma_{\mathrm{s}, \text { as }}(J)=\frac{112 \pi^{4}}{15} \frac{g(J) h c B_{0}\left(\omega_{0}+\Delta \omega_{\mathrm{s}, \text { as }}(J)\right)^{4} \gamma^{2}}{(2 I+1)^{2} k T} b(J)_{\mathrm{s}}$,

asexp $\left(-\frac{E_{J}}{k T}\right)$,

where $g(J)$ denotes the statistical weight factor, $I$ the nuclear spin, $\omega_{0}$ the frequency of the incident light, $\Delta \omega_{\mathrm{s} \text {, as }}(J)$ the frequency shift, $\gamma$ the anisotropy of the molecularpolarizability tensor, $h$ Planck's constant, $c$ the velocity of light, $k$ Boltzmann's constant, $T$ temperature and $B_{0}$ the rotational constant. The factors $b(J)_{\mathrm{s}, \text { as }}$ for Stokes and antiStokes lines are

$b_{\mathrm{s}}(J)=\frac{(J+1)(J+2)}{(2 J+3)}, \quad b_{\mathrm{as}}(J)=\frac{J(J-1)}{(2 J-1)}$,

and the frequency shifts are

$\Delta \omega_{\mathrm{s}}(J)=-(4 J+6) B_{0}, \quad \Delta \omega_{\mathrm{as}}(J)=(4 J-2) B_{0}$.

The rotational energy is approximated as $E_{J}=J(J+$ 1) $h c B_{0}$; the values of $g(J), I, \gamma$ for molecules of nitrogen and oxygen were taken from Behrendt and Nakamura (2002).

Figure 3 shows the RR spectra of $\mathrm{N}_{2}$ and $\mathrm{O}_{2}$ molecules weighted with the corresponding number density fractions in the atmosphere for a laser wavelength of $532.12 \mathrm{~nm}$ and $T=300 \mathrm{~K}$. The spectrum includes Stokes and anti-Stokes branches and spreads over several nanometers on both sides of the stimulating laser wavelength. In our implementation, the filter transmitted only a portion of the anti-Stokes branch

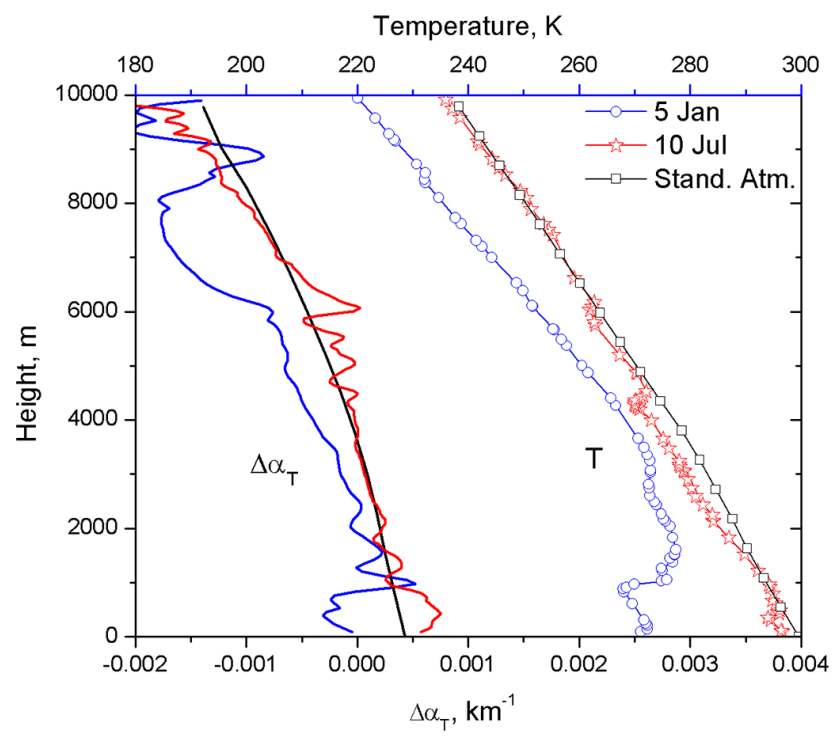

Figure 6. Temperature profiles (open symbols) and errors of extinction coefficient calculation $\Delta \alpha_{\mathrm{T}}$ due to height variation of temperature (solid lines). Computations were performed for US Standard Atmosphere temperature profile (black) and for temperature measured by radiosonde on 5 January (blue) and 10 July 2013 (red).

in order to have the possibility to shift the filter transmission band toward shorter wavelengths by filter tilting, if necessary. The effective differential cross section $\sigma_{\mathrm{RR}}^{\text {eff }}$ of the atmosphere is obtained by summing the cross sections $\sigma_{i J}=\sigma_{\text {as }}^{i}(J)$ of the individual RR lines of molecules at their respective wavelengths $\lambda_{i J}$ :

$\sigma_{\mathrm{RR}}^{\mathrm{eff}}=\sum_{i} \sum_{J} \eta_{i} \xi_{\mathrm{R}}\left(\lambda_{i, J}\right) \sigma_{i J}$

The indices $i=1$ and 2 correspond to $\mathrm{N}_{2}$ and $\mathrm{O}_{2}$ molecules; $\eta_{i}$ are the density fractions of these molecules in atmosphere.

The frequency shift of rotational lines with respect to the frequency of the laser radiation is small compared with vibrational scattering, so in practice the spectral dependence of particle extinction can be neglected. Thus the expressions (4, 5) for backscattering and extinction coefficient become

$\beta^{\text {aer }}(z)=-\beta^{\text {mol }}(z)+\beta^{\text {mol }}\left(z_{0}\right) \cdot \frac{P_{\mathrm{R}}\left(z_{0}\right) P_{L}(z) N(z) \sigma_{\mathrm{RR}}^{\text {eff }}(z)}{P_{L}\left(z_{0}\right) P_{\mathrm{R}}(z) N\left(z_{0}\right) \sigma_{\mathrm{RR}}^{\text {eff }}\left(z_{0}\right)}$,
$\alpha^{\text {aer }}(z)=\frac{1}{2} \frac{\mathrm{d}}{\mathrm{d} z} \ln \left[\frac{N(z)}{P_{\mathrm{R}}(z) z^{2}}\right]+\frac{1}{2} \frac{\mathrm{d}}{\mathrm{d} z} \ln \left[\sigma_{\mathrm{RR}}^{\text {eff }}(z)\right]-\alpha^{\mathrm{mol}}(z)$.

Using notation $X(z)=\frac{\sigma_{\mathrm{R}}^{\text {eff }}(z)}{\sigma_{\mathrm{RR}}^{\text {eff }}(z 0)}$, the error of $\beta^{\text {aer }}$ computation $\left(\varepsilon_{\beta}^{T}\right)$ due to neglecting the height variation of temperature $(X=1)$ can be estimated from Eq. (16) as

$\varepsilon_{\beta}=\frac{\beta^{\text {aer }}-\beta_{X=1}^{\text {aer }}}{\beta^{\text {aer }}}=\frac{\beta^{\text {tot }}}{\beta^{\text {tot }}-\beta^{\text {mol }}} \frac{X-1}{X}=\frac{R}{R-1} \frac{X-1}{X}$. 


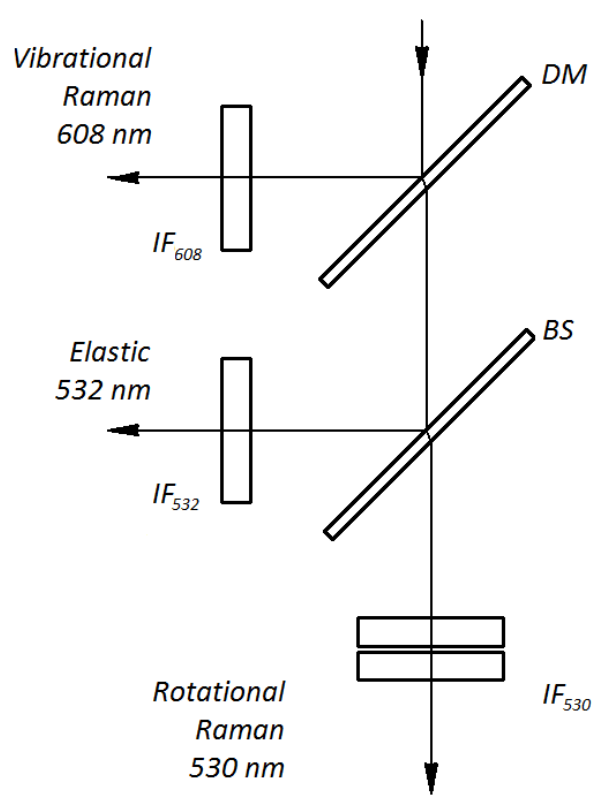

Figure 7. Optical scheme of spectral separation of Raman signals in the receiving module. DM is a dichroic $608 / 532 \mathrm{~nm}$ mirror, and BS is the beam splitter reflecting about $10 \%$ at $532 \mathrm{~nm}$ for both $\mathrm{s}$ and $\mathrm{p}$ polarizations.

Here $R$ is the scattering ratio $\frac{\beta^{\text {tot }}}{\beta^{\text {mol }}}$. For $\beta^{\text {aer }}>>\beta^{\text {mol }}$ the error $\varepsilon_{\beta}^{T}$ becomes $\frac{X-1}{X}$, while for low aerosol loading there is an enhancement factor of $\frac{R}{R-1}$.

The influence of temperature dependence of $\sigma_{\mathrm{RR}}^{\text {eff }}$ on extinction calculation $\left(\Delta \alpha_{\mathrm{T}}\right)$ is given by the second term in Eq. (17).

$\Delta \alpha_{\mathrm{T}}=\frac{1}{2} \frac{\mathrm{d}}{\mathrm{d} z} \ln \left[\sigma_{\mathrm{RR}}^{\text {eff }}(z)\right]$

This term can be significant in the presence of strong temperature gradients. To quantify the possible uncertainties in the evaluation of backscattering and extinction coefficients arising from the temperature dependence of $\sigma_{\mathrm{RR}}^{\text {eff }}$, numerical simulation studies were performed. The RR line with least temperature sensitivity for the $532.12 \mathrm{~nm}$ laser line is in the vicinity of $530.4 \mathrm{~nm}(J=11)$ for $\mathrm{O}_{2}$ and in the vicinity of $530.2 \mathrm{~nm}(J=9)$ for $\mathrm{N}_{2}$, so centering the filter transmission band near these values will minimize the sensitivity of $\sigma_{\mathrm{RR}}^{\text {eff }}$ to changes in temperature. When choosing filter parameters the desire is to maximize the cross section $\sigma_{\mathrm{RR}}^{\text {eff }}$ by including only the strongest rotational lines since unnecessarily wide transmission band will lead to an increase of the sky background noise and an overall decrease in signal-to-noise ratio under daytime conditions.

Figure 4 shows the change of $\frac{X-1}{X}$ as a function of temperature for the spectral intervals 530.0-530.5, 529.7-530.7 and $529.2-531.2 \mathrm{~nm}$. Computations were performed with T varying in the range $230-300 \mathrm{~K}$ where the reference temperature $T_{0}$ was taken to be $T_{0}=300 \mathrm{~K}$. For all intervals the relative

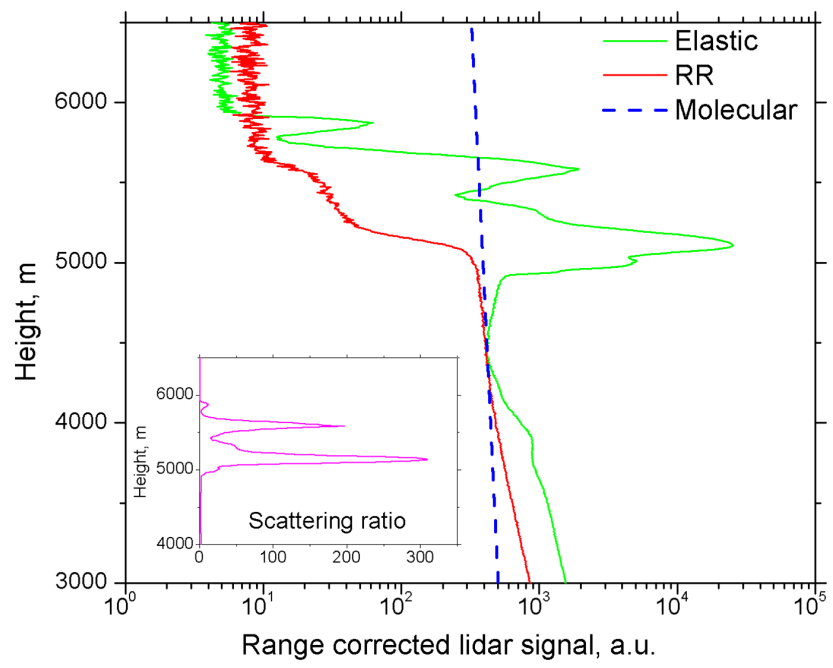

Figure 8. Range-corrected elastic $532 \mathrm{~nm}$ and RR lidar signals in the presence of clouds. Model signal of molecular scattering is indicated by dash line, and the profile of scattering ratio is shown as an insert.

change of RR scattering cross section $\frac{X-1}{X}=\frac{\sigma_{\mathrm{RR}}^{\text {eff }}(T)-\sigma_{\mathrm{RR}}^{\text {eff }}\left(T_{0}\right)}{\sigma_{\mathrm{RR}}^{\text {eff }}(T)}$ does not exceed $3.5 \%$. The ratios of $\sigma_{\mathrm{RR}}^{\text {eff }}\left(T_{0}\right)$ to the total cross section of the anti-Stokes branch for these three intervals are $0.2,0.37$ and 0.7. Of these intervals, that of 529.2 $531.2 \mathrm{~nm}$ is the most attractive, as it contains approximately $70 \%$ of the entire anti-Stokes Raman signal and possesses a small temperature dependence (the variation of $\sigma_{\mathrm{RR}}^{\text {eff }}$ is below $1.0 \%$ ). Based on these considerations, we chose this interval as the target for the interference filter design.

The transmission spectrum of the interference filter used in our experiments, taken from the manufacturer's data sheet (Alluxa, CA, USA), is shown in Fig. 3. The filter has a transmission greater than $95 \%$ at the peak, with bandwidth of approximately $2.3 \mathrm{~nm}$ full width at half maximum (FWHM). Suppression of the elastic scattering is achieved by using two filters in tandem, where each filter possesses OD $>4$ at $532.12 \mathrm{~nm}$. The temperature dependence of $\frac{X-1}{X}$ for this filter is also shown in Fig. 4. To get the effective scattering cross section, the filter transmission was convolved with the Raman spectrum in accordance with Eq. (14). The variation of $\sigma_{\mathrm{RR}}^{\text {eff }}$ in the $230-300 \mathrm{~K}$ temperature range does not exceed $1 \%$. The temperature dependence of the particle backscattering coefficient can be accounted for by computing $X(z)$ from Eq. (16) and using an atmosphere model or radiosonde measurement for density. Figure 5 shows $X(z)$ computed for the US Standard Atmosphere model up to $10 \mathrm{~km}$ height; the reference height is taken at $z=0$. The value of $X$ in this height range does not change by more than $1 \%$, so in many practical cases $X=1$ can be used.

The error of the extinction coefficient calculation $\Delta \alpha_{\mathrm{T}}$ induced by the temperature height variation depends, as follows from Eq. (17), on the gradient of the temperature pro- 


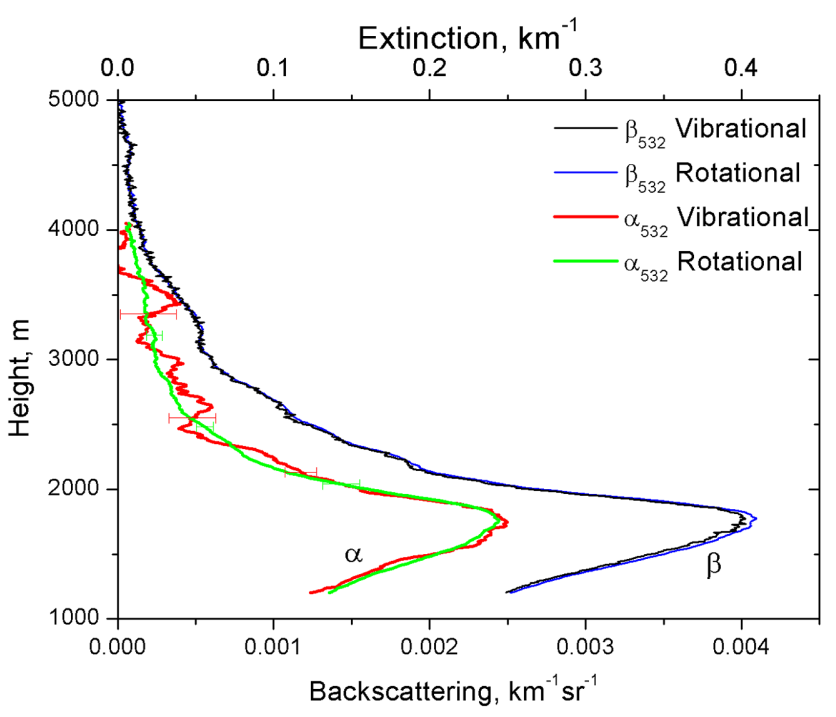

Figure 9. Particle backscattering and extinction coefficients at $532 \mathrm{~nm}$ computed with the use of vibrational and rotational Raman scattering on 18 June 2014.

file. To estimate this error, we have tested the temperature profiles from the US Standard Atmosphere model and from radiosonde launches performed at Dulles International Airport, VA, in the vicinity of Washington, D.C. The results of the computations are shown in Fig. 6. To calculate the range derivative from discrete temperature measurements, a cubic spline over seven points was used. For the model temperature profile the decrease of the temperature with height provides a negative contribution to the calculated particle extinction. The error $\Delta \alpha_{\mathrm{T}}$ varies with height, but it is below $0.002 \mathrm{~km}^{-1}$ for the heights up to $10 \mathrm{~km}$. The same figure shows also the results for radiosonde launches on 5 January and 10 July 2013. The corresponding temperature profiles present low-scale oscillations; still for both days, $\Delta \alpha_{\mathrm{T}}<0.002 \mathrm{~km}^{-1}$. Computations performed for days in different seasons have demonstrated that, in general, temperature variations contribute an error in calculated extinction of less than $2 \%$ for extinction values of $0.1 \mathrm{~km}^{-1}$ and greater.

Narrowband interference filters that are normally used in lidar receivers select mainly the Q-branch of the nitrogen vibrational-rotational Raman spectrum. Using the corresponding scattering cross section for the Q-branch of nitrogen $\left(\sigma_{\mathrm{N} 2}^{\mathrm{Q}}\right.$, vib $)$ provided by Inaba for the $337.1 \mathrm{~nm}$ laser line and recalculating it for $532.12 \mathrm{~nm}$, we estimate that for density fraction $\eta_{\mathrm{N}_{2}}=0.79$ and $\eta_{\mathrm{O}_{2}}=0.21$ the ratio $\frac{\eta_{\mathrm{N}_{2}} \sigma_{\mathrm{N}_{2}}^{\mathrm{O}+\mathrm{S}}+\eta_{\mathrm{O}_{2}} \sigma_{\mathrm{O}_{2}}^{\mathrm{O}+\mathrm{S}}}{\eta_{\mathrm{N}_{2}} \sigma_{\mathrm{N}_{2}}^{\mathrm{O}, \text { rib }}}$ is about 51. Here $\sigma_{\mathrm{N}_{2}}^{\mathrm{O}+\mathrm{S}} \mathrm{O}_{2}$ refer to $\mathrm{N}_{2}$ and $\mathrm{O}_{2}$ total RR cross sections, including both Stokes and antiStokes branches. Considering a temperature of $270 \mathrm{~K}$, the filter shown in Fig. 3 transmits approximately $73 \%$ of the total anti-Stokes components for nitrogen and oxygen. We therefore estimate that the scattered power in the RR channel is a

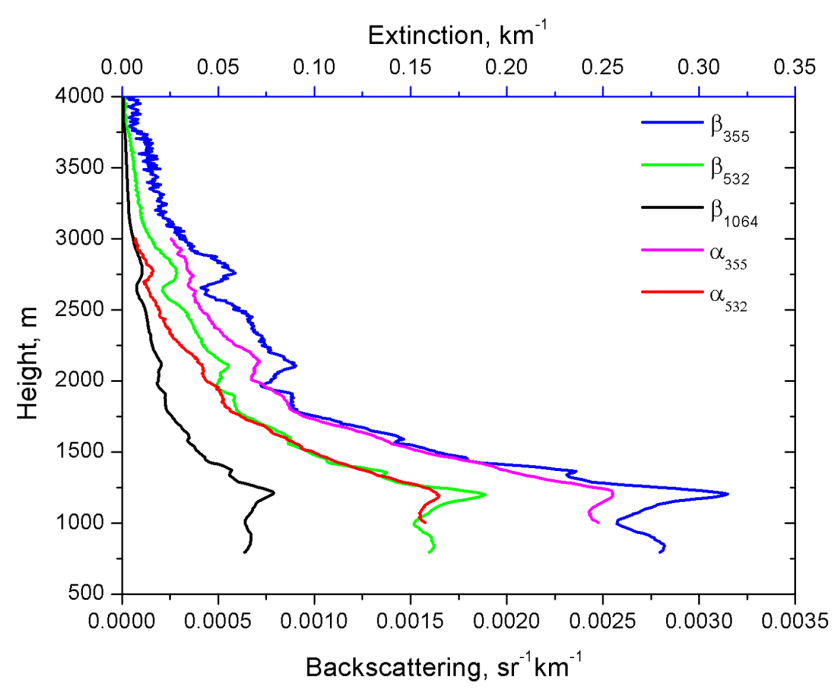

Figure 10. Vertical profiles of $3 \beta+2 \alpha$ measurements on 1 July 2014. Extinction coefficient at $532 \mathrm{~nm}$ is calculated from RR signal.

factor of 22 higher than that of the vibrational nitrogen Raman channel at $608 \mathrm{~nm}$ (using a filter transmission of $70 \%$ for the vibrational channel).

\subsection{Modification of GSFC Raman lidar system}

A description of the NASA GSFC multiwavelength Raman lidar is presented in Veselovskii et al. (2013). Our experience in inverting time series of $3 \beta+2 \alpha$ measurements to particle microphysical properties has demonstrated that uncertainties of the retrieved parameters are related mainly to the random uncertainty of the $\alpha_{532}$ data, which in turn is due to insufficient power of the $608 \mathrm{~nm}$ backscatter signal (Veselovskii et al., 2013). This is in agreement with the sensitivity studies performed by Perez-Ramirez et al. (2013) although these latter results point out the additional importance of systematic biases in the input optical data. To incorporate RR channel at $530 \mathrm{~nm}$, the lidar receiving module was modified as shown in Fig. 7. This optical configuration permitted simultaneous measurements of the vibrational and rotational Raman signals. The spectral components at 608 and $532 \mathrm{~nm}$ were separated by a dichroic mirror (DM) with approximately $95 \%$ of nitrogen vibrational Raman backscatter being reflected to $608 \mathrm{~nm}$ channel. The beam splitter (BS) shown in Fig. 7 then reflected approximately $10 \%$ portion of the 532 signal into the Mie channel, with more than $85 \%$ being transmitted into the RR channel. Two normally installed interference filters (IFs), each possessing the characteristics shown in Fig. 3, were used together to provide more than 8 orders of magnitude of rejection of the elastic signal. The Mie 532 and RR $530 \mathrm{~nm}$ signals were measured by R1924 Hamamatsu PMTs (photomultiplier tubes), while in $608 \mathrm{~nm}$ channel a Hamamatsu R9880-20 PMT was used. To compare the scattered 


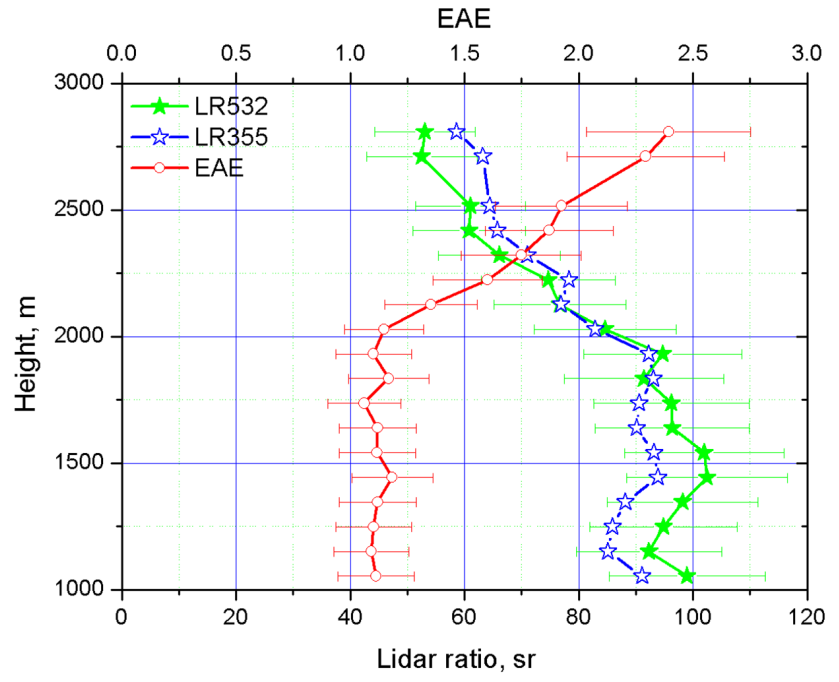

Figure 11. Extinction Ångström exponent (EAE) and lidar ratios at 355 and $532 \mathrm{~nm}$ on 1 July 2014.

power in 608 and $530 \mathrm{~nm}$ channels, we made two sequential measurements using the same R1924 PMT for both channels. After correction for difference in quantum efficiency of the photocathode at 608 and $530 \mathrm{~nm}$, we estimate the enhancement of scattered power in the RR channel compared with the vibrational one to be more than a factor 10 .

The initial measurements were taken under cloudy conditions to test the blocking of the Mie scattering by the RR filters. An example of such a test is given in Fig. 8, showing elastic and RR range-corrected lidar signals in the presence of clouds. Measurements were performed during nighttime, and $4 \times 10^{5}$ laser pulses were accumulated. The scattering ratio at $532 \mathrm{~nm}$ inside the $5000-6000 \mathrm{~m}$ height layer increases up to 300 ; still no enhancement of the signal measured in the RR channel is observed.

Figure 9 shows backscattering and extinction coefficients at $532 \mathrm{~nm}$ calculated from vibrational and rotational Raman scattering during nighttime on 18 June; $9 \times 10^{4}$ laser pulses were accumulated during the measurement. An elevated aerosol layer has a maximum value of $\alpha_{532} \approx 0.25 \mathrm{~km}^{-1}$ at approximately $1750 \mathrm{~m}$, and the extinction Ångström exponent at this height calculated from Raman measurements at 355 and $532 \mathrm{~nm}$ was about 1.0 , so the range-independent value $A=1.0$ was used for Raman computations at both wavelengths. In the height range $1000-5000 \mathrm{~m}$ the temperature changes were within an interval of $25^{\circ}$ and the error in the calculation of the backscattering coefficient due to temperature variation was below $1.0 \%$. The largest difference between backscattering profiles was observed at the maximum of the scattering layer and did not exceed $2 \%$. The presented extinction profiles clearly demonstrate the improvement of the extinction calculation when the RR signal at $530 \mathrm{~nm}$ is used instead of that of vibrational scattering at $608 \mathrm{~nm}$.

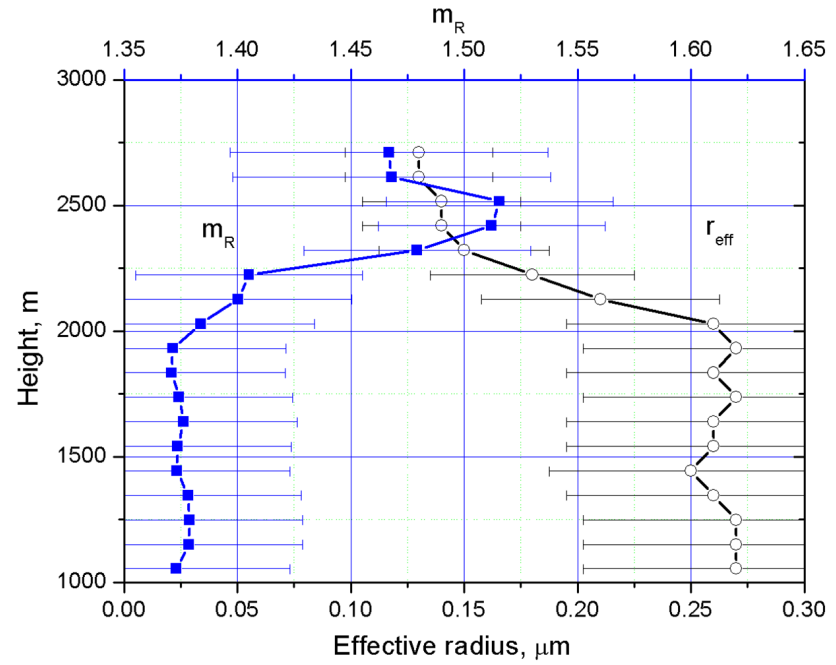

Figure 12. The profiles of effective radius and the real part of the refractive index derived from $3 \beta+2 \alpha$ measurements on 1 July 2014.

After these test measurements were performed, the $608 \mathrm{~nm}$ beam splitter was removed from the receiver to maximize the RR signal at $530 \mathrm{~nm}$ and the system was used for regular observations. An example of vertical profiles of $3 \beta+2 \alpha$ measurements made on 1 July 2014 is given in Fig. 10. The measurements were performed during nighttime from 01:00 to 01:30 UTC. Figure 11 shows the lidar ratios at 355 and $532 \mathrm{~nm}$ and the extinction Ångström exponent calculated from the optical data averaged in $100 \mathrm{~m}$ height bins. The lidar ratio below $2000 \mathrm{~m}$ is about $90 \mathrm{sr}$ for both wavelengths, but above $2000 \mathrm{~m}$ the lidar ratios gradually decrease. The Ångström exponent rises above $2000 \mathrm{~m}$ from 1.2 to 2.3 at $2750 \mathrm{~m}$, indicating that the aerosol layer above $2000 \mathrm{~m}$ contains smaller particles.

The $3 \beta+2 \alpha$ measurements were inverted to particle microphysical properties using inversion with regularization as described in Veselovskii et al. (2002). Vertical profiles of the effective radius and the real part of the refractive index are shown in Fig. 12. Up to $2000 \mathrm{~m}$ the effective radius is about $0.26 \mu \mathrm{m}$, and above that height it decreases, reaching $0.13 \mu \mathrm{m}$ above $2500 \mathrm{~m}$. Simultaneously with the decrease of $r_{\text {eff }}$, the real part $\mathrm{m}_{R}$ increases from 1.37 to approximately 1.50 . Thus above $2000 \mathrm{~m}$ there is a layer with a different particle type possessing smaller size and higher $m_{\mathrm{R}}$

\section{Summary and conclusion}

The simultaneous use of Mie and vibrational Raman nitrogen backscattering signals in lidars has permitted useful retrievals of particle extinction and backscattering coefficients. However, vibrational Raman measurements are characterized by a significant frequency shift of the return signal from the stimulating one, introducing uncertainties due to 
the wavelength scaling of particle scattering. The absence of such a frequency shift has been one of the advantages of the technologically more complex approach of high-spectralresolution lidar for the task of measuring aerosols with a sufficient number of wavelengths to support microphysical inversions. As in the HSRL technique, the use of rotational Raman scattering, instead of vibrational scattering, essentially removes the concern due to wavelength scaling while simultaneously permitting measurements to take advantage of a much larger cross section. For the case of measurements made using the $532 \mathrm{~nm}$ stimulating wavelengths, the RR signals at $532 \mathrm{~nm}$ are also improved versus the vibrational Raman ones at $608 \mathrm{~nm}$ due to the typically higher quantum efficiency of detectors operating at $532 \mathrm{~nm}$. We have presented a practical approach to implementing rotational Raman measurements in multiwavelength aerosol lidar using sharp-edge interference filters to separate the RR and Mie signals. During the design phase of the development, numerical simulations were performed demonstrating that a measurement of aerosol extinction could be made with low temperature dependence using a portion of either anti-Stokes or Stokes components. This selection also achieved a signal increase of more than a factor or 10 when compared with vibrational nitrogen. In most cases, this permits filters with larger FWHM to be used for the extinction measurement while still increasing the overall signal-to-noise ratio even under daytime conditions. Upgraded this way, the NASA GSFC multiwavelength Raman lidar has demonstrated improved capabilities for $\alpha_{532}$ measurements, which in turn have improved the inversion of $3 \beta+2 \alpha$ optical data to particle microphysics.

The next step in our plans is to test the use of the RR signal at $355 \mathrm{~nm}$ instead of $387 \mathrm{~nm}$ due to vibrational scattering. Though quite capable signal strengths can be achieved using vibrational nitrogen signals at $387 \mathrm{~nm}$, the issue of wavelength scaling still remains. The modeling performed here shows that when the aerosol layers with high optical depth are considered errors due to wavelength scaling for Raman vibrational measurements can be larger at $355 \mathrm{~nm}$ than at $532 \mathrm{~nm}$. Thus the prospect of achieving $3 \beta+2 \alpha$ measurements using RR scattering for both extinction measurements is attractive and will be the focus of future development.

Acknowledgements. Development of lidar retrieval algorithms was partly supported by the Russian Science Foundation (project no. 14-50-00034).

Edited by: U. Wandinger

\section{References}

Achtert, P., Khaplanov, M., Khosrawi, F., and Gumbel, J.: Pure rotational-Raman channels of the Esrange lidar for temperature and particle extinction measurements in the tropo- sphere and lower stratosphere, Atmos. Meas. Tech., 6, 91-98, doi:10.5194/amt-6-91-2013, 2013.

Adam, M.: Notes on Temperature-Dependent Lidar Equations, J. Atmos. Ocean. Tech., 26, 1021-1039, 2009.

Ansmann, A. and Müller, D.: Lidar and atmospheric aerosol particles, in: Lidar, Range-Resolved Optical Remote Sensing of the Atmosphere, Weitkamp, C. ed., Springer, New York, 105-141, 2005.

Ansmann, A., Riebesell, M., Wandinger, U., Weitkamp, C., Voss, E., Lahmann, W., and Michaelis, W.: Combined Raman elasticbackscatter lidar for vertical profiling of moisture, aerosols extinction, backscatter, and lidar ratio, Appl. Phys. B, 55, 18-28, 1992.

Arshinov, Y., Bobrovnikov, S., Serikov, I., Ansmann, A., Wandinger, U., Althausen, D., Mattis, I., and Müller, D.: Daytime operation of a pure rotational Raman lidar by use of a FabryPerot interferometer, Appl. Opt., 44, 3593-3603, 2005.

Balin, I., Serikov, I., Bobrovnikov, S., Simeonov, V., Calpini, B., Arshinov, Y.,and Van Den Bergh, H.: Simultaneous measurement of atmospheric temperature, humidity, and aerosol extinction and backscatter coefficients by a combined vibrational-purerotational Raman lidar, Appl. Phys. B, 79, 775-782, 2004.

Behrendt, A. and Reichardt, J.: Atmospheric temperature profiling in the presence of clouds with a pure rotational Raman lidar by use of an interference-filter-based polychromator, Appl. Optics, 39, 1372-1378, 2000.

Behrendt, A. and Nakamura, T. : Calculation of the calibration constant of polarization lidar and its dependency on atmospheric temperature, Opt. Express, 10, 805-817, 2002.

Behrendt, A., Nakamura, T., Onishi, M., Baumgart, R., and Tsuda, T.: Combined Raman lidar for the measurement of atmospheric temperature, water vapor, particle extinction coefficient, and particle backscatter coefficient, Appl. Optics, 41, 7657-7666, 2002.

Bohren C. F. and Huffmann D. R.: Absorption and Scattering of Light by Small Particles, Wiley, 1983.

David, G., Thomas, B., Nousiainen, T., Miffre, A., and Rairoux, P.: Retrieving simulated volcanic, desert dust and sea-salt particle properties from two/three-component particle mixtures using UV-VIS polarization lidar and T matrix, Atmos. Chem. Phys., 13, 6757-6776, doi:10.5194/acp-13-6757-2013, 2013.

Di Girolamo, P., Marchese, R., Whiteman, D. N., and Demoz, B.: Rotational Raman Lidar measurements of atmospheric temperature in the UV, Geophys. Res. Let., 31, L01106, doi:10.1029/2003GL018342, 2004.

Di Girolamo, P., Behrendt, A., and Wulfmeyer, V.: Spaceborne profiling of atmospheric temperature and particle extinction with pure rotational Raman Lidar and of relative humidity in combination with differential absorption lidar: performance simulations, Appl. Opt., 45, 2474-2494, 2006.

Dubovik, O., Holben, B. N., Eck, T. F., Smirnov, A., Kaufman, Y. J., King, M. D., Tanré, D., and Slutsker, I.: Variability of absorption and optical properties of key aerosol types observed in worldwide locations, J. Atmos. Sci., 59, 590-608, 2002.

Eloranta, E. E.: High spectral resolution lidar, in: Lidar, RangeResolved Optical Remote Sensing of the Atmosphere, edited by: Weitkamp, C., Springer, New York, 143-164, 2005.

Granados-Muñoz, M. J., Guerrero-Rascado, J. L., Bravo-Aranda, J. A., Navas-Guzmán, F., Valenzuela, A., Lyamani, H., Chaikovsky, A., Wandinger, U., Ansmann, A., and Dubovik, O: Retrieving 
aerosol microphysical properties by Lidar-Radiometer Inversion Code (LIRIC) for different aerosol types, J. Geophys. Res.Atmos., 119, 4836-4858, 2014.

Guan, H., Schmid, B., Bucholtz, A., and Bergstrom, R.: Sensitivity of shortwave radiative flux density, forcing, and heating rate to the aerosol vertical profile, J. Geophys. Res. 115, D06209, doi:10.1029/2009JD012907, 2010.

Herzberg, G.: Molecular Spectra and Molecular Structure, Spectra of Diatomic Molecules, 2nd ed., Van Nostrand Reinhold, 1, 658 pp., 1950.

Inaba, H.: Detection of atoms and molecules by Raman scattering and resonance fluorescence, in: Laser Monitoring of the Atmosphere, edited by: Hinkley, E. D., of Topics in Applied Physics (Springer-Verlag, Berlin), 14, 153-232, 1976.

IPCC: Summary for Policymakers, In Climate Change 2013: The Physical Science Basis, Contribution of Working Group I to the Fifth Assessment Report of the Intergovernmental Panel on Climate Change, edited by: Stocker, T. F., Qin, D., Plattner, G.- K., Tignor, M., Allen, S. K., Boschung, J., Nauels, A., Xia, Y., Bex, V., and Midgley, P. M., Cambridge, UK, Cambridge University Press, 2013.

Kim, D. and Cha, H.: Rotational Raman Lidar: Design and Performance Test of Meteorological Parameters (Aerosol Backscattering Coefficients and Temperature), J. Kor. Phys. Soc. 51, 352357, 2007

Long, D. A.: The Raman Effect, A united treatment of the theory of Raman scattering by molecules, Wiley, NewYork, 2002.

Lopatin, A., Dubovik, O., Chaikovsky, A., Goloub, P., Lapyonok, T., Tanré, D., and Litvinov, P.: Enhancement of aerosol characterization using synergy of lidar and sun-photometer coincident observations: the GARRLiC algorithm, Atmos. Meas. Tech., 6, 2065-2088, doi:10.5194/amt-6-2065-2013, 2013.

Müller, D., Wandinger, U., and Ansmann, A.: Microphysical particle parameters from extinction and backscatter lidar data by inversion with regularization: theory, Appl. Opt. 38, 2346-2357, 1999.

Müller, D., Hostetler, C. A., Ferrare, R. A., Burton, S. P., Chemyakin, E., Kolgotin, A., Hair, J. W., Cook, A. L., Harper, D. B., Rogers, R. R., Hare, R. W., Cleckner, C. S., Obland, M. D., Tomlinson, J., Berg, L. K., and Schmid, B.: Airborne Multiwavelength High Spectral Resolution Lidar (HSRL-2) observations during TCAP 2012: vertical profiles of optical and microphysical properties of a smoke/urban haze plume over the northeastern coast of the US, Atmos. Meas. Tech., 7, 3487-3496, doi:10.5194/amt-7-3487-2014, 2014.

O’Neill, N. T., Eck, T. F., Holben, B., Smirnov, A., and Dubovik, O.: Bimodal size distribution influences on the variation of Ångström derivatives in spectral and optical depth space, J. Geophys. Res., 106, 9787-9806, 2001.
Penney, C. M., Peters St., R. L., and Lapp, M. : Absolute rotational Raman cross sections for $\mathrm{N}_{2}, \mathrm{O}_{2}$, and $\mathrm{CO}_{2}$, J. Opt. Soc. Amer., 64, 712-716, 1974.

Pérez-Ramírez, D., Whiteman, D. N., Veselovskii, I., Kolgotin, A., Korenskiy, M., and Alados-Arboledas, L.: Effects of systematic and random errors on the retrieval of particle microphysical properties from multiwavelength lidar measurements using inversion with regularization, Atmos. Meas. Tech., 6, 3039-3054, doi:10.5194/amt-6-3039-2013, 2013.

Radlach, M., Behrendt, A., and Wulfmeyer, V.: Scanning rotational Raman lidar at $355 \mathrm{~nm}$ for the measurement of tropospheric temperature fields, Atmos. Chem. Phys., 8, 159-169, doi:10.5194/acp-8-159-2008, 2008.

Rolf, C., Krämer, M., Schiller, C., Hildebrandt, M., and Riese, M.: Lidar observation and model simulation of a volcanicash-induced cirrus cloud during the Eyjafjallajökull eruption, Atmos. Chem. Phys., 12, 10281-10294, doi:10.5194/acp-1210281-2012, 2012.

Tesche, M., Ansmann, A., Müller, D., Althausen, D., Engelmann, R., Freudenthale,r V., and Groß, S.: Vertically resolved separation of dust and smoke over Cape Verde by using multiwavelength Raman and polarization lidar during SAMUM 2008, J. Geophys. Res., 114, D13202, doi:10.1029/2009JD011862, 2009.

Veselovskii, I., Kolgotin, A., Griaznov, V., Müller, D., Wandinger, U., and Whiteman, D.: Inversion with regularization for the retrieval of tropospheric aeroso-l parameters from multiwavelength lidar sounding, Appl. Opt., 41, 3685-3699, 2002.

Veselovskii, I., Whiteman, D. N., Korenskiy, M., Kolgotin, A., Dubovik, O., Perez-Ramirez, D., and Suvorina, A.: Retrieval of spatio-temporal distributions of particle parameters from multiwavelength lidar measurements using the linear estimation technique and comparison with AERONET, Atmos. Meas. Tech., 6, 2671-2682, doi:10.5194/amt-6-2671-2013, 2013.

Whiteman, D. N.: Examination of the traditional Raman lidar technique. I. Evaluating the temperature-dependent lidar equations, Appl. Opt., 42, 2571-2592, 2003a.

Whiteman, D. N.: Examination of the traditional Raman lidar technique. II. Evaluating the ratios for water vapor and aerosols, Appl. Opt., 42, 2593-2608, 2003b.

Whiteman, D. N., Veselovskii, I., Cadirola, M., Rush, K., Comer, J., Potter, J. R., and Tola, R.: Demonstrations measurements of water vapor, cirrus clouds, and carbon dioxide using a highperformance Raman lidar, J. Atmos. Ocean. Technol. 24, 13771388, 2007.

Wagner, J., Ansmann, A., Wandinger, U., Seifert, P., Schwarz, A., Tesche, M., Chaikovsky, A., and Dubovik, O.: Evaluation of the Lidar/Radiometer Inversion Code (LIRIC) to determine microphysical properties of volcanic and desert dust, Atmos. Meas. Tech., 6, 1707-1724, doi:10.5194/amt-6-1707-2013, 2013. 